\title{
Pluriglandular Syndromes with Gynecomasty in Leprous Subjects
}

\author{
Claudio Natali and Samuele Caffarena.
}

(Precis of an article published in the "Revista Sud-Americana de Endochrinologia, Immunologia y Quimioterapia," Vol. XV, Jan. \& Feb., 1932, Nos. 1 \& 2).

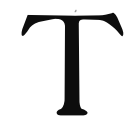

$\mathrm{HE}$ authors point out the high percentage (14 per cent.) of gynecomasty observed amongst 60 cases of leprosy examined at the lazar-house of $\mathrm{S}$. Isabel in Asuncion. They discuss six cases which have been studied by them clinically as regards the " endocrina " syndrome, and histologically as regards the breasts by biopsy.

1 st Case. A man of 44, suffering for 12 years, of the maculoanæsthetic type. $\mathrm{He}$ is a tardy hypogenital with signs of hyperthyroidism and bilateral gynecomasty, but only marked and of the true type on the left side. This gynecomasty must have started some four months ago, and for the last two days the left breast has been painful, the pain being increased by pressure. There is orchi-epididimitis.

2nd Case. A man of 27, his father and brothers leprous. His illness started nine years ago and it is a mixed form of leprosy, mutilating, not uniform. There are evident signs of dysthyroidism of the old basedowian type; and sexual impotence with secondary sexual characteristics tending towards the feminine type, together with gynecomasty. The latter developed five months ago, and is bilateral and true, and it represents the breasts of a young girl at the time of puberty. The patient has had a painful attack in the left breast accompanied by inflammation. There is orchi-epididi ${ }^{~}$ is, although not serious enough, at least clinically.

3rd Case. A man of 25 years, declared leprous 10 years ago and affected by combined leprosy of the prevailing macular type. In this case a constitutional hormonic deficiency of the sexual glands can be admitted. At present the patient is a hypogenital with obvious signs of hyposubrenalism, accompanied by other numerous and slight signs of hyperthyroidism. Bilateral gynecomasty of the true type has lasted for the last 12 months, and at present the breasts have reached the size of an orange. There have been repeated attacks of pain at irregular intervals lasting for some days, and inflammation of the organ. There is leprous orchi-epididimitis.

4th Case. A man of 30 . He is a beautiful example of eunuchism combined with the characteristics of the xeroderma dystrophico of Rummo-Ferrannini and of the feminine ennuchism of Tende. He has been interned in the lazar house for the last eight years : he was already leprous before then, but the date of the beginning of the illness cannot be established. At present the disease is in the maculoanæsthetic state. Puberty at 15 , very slow. True gynecomasty has prevailed for the last three years, the breasts being similar to those of a woman. Painful attacks with increase of volume and inflammation of the breasts recur at irregular intervals and last for several days, during which the nipples become more prominent and the 
"rings" more coloured. There is leprous orchi-epididimitis to an appreciable extent only on the right side, and the smallness of the left testicle shows the hypoplasic congenital state of the genital glands.

5th Case. A man of 26. At the age of 17 he was declared leprous and not yet pubescent. $\mathrm{He}$ presents a pluriglandular syndrome in which the signs of eunuchism of the first variety of Tende predominate over those of dysthyroidism, with characteristics of hyperthyroidism, and over those of hypo-adrenalism. True gynecomasty has prevailed for the last three or four years. Also in this case there are periods in which the breasts become painful and increase in volume. There is chronic leprous orchi-epididimitis with occasional febrile exacerbation.

6th Case. A man of 44, affected by pustulous leprosy. The illness started 17 years ago. Bilateral gynecomasty developed four years after the beginning of leprosy; there was a slow progression for two years, after which the breasts lost their firm contour and became flaxid and drooping, presenting the appearance of those of an old woman whose breasts have never functioned. Painful crisis absent. Only for the last seven or eight months the patient has noticed disproportion in his skeleton. At present the vulgarity of the leprous picture disappears before the beauty and interest offered by the endocrine syndrome represented by typical acromegale associated with tardy hypogenitalism and true gynecomasty. There is grave leprous orchi-epididimitis.

The authors assert in the first place that the generalisation of the phrase " rudimentary gland " for the masculine breast is unsuitable, particularly when individual pathological problems are to be considered. It would be imprudent, at least, to-day, to base scientific reasoning on "axiomatic notions" in view of the numerous fluctuations in the individual characteristics, somatic and organic, which exist without, however, exceeding normal limits. Therefore, they conclude that in the case of the male breasts individual variations of structure must be admitted; and hence it is not illogical to think that individual anatomical conditions, consisting perhaps of a greater abundance of glandular tissue with a higher or lower vitality are essential in order to determine a true gynecomasty, while there are special pathological conditions which enhance them.

After a thorough discussion on the histological aspect or discovery of the breasts under examination, and on the determination of gynecomasty and its frequency in leprosy, the authors go on to describe the aetiopathogenesis of the endocrine syndrome under consideration and the biological meaning of gynecomasty, and they came to the following conclusions :-

1. Gynecomasty is frequent in the leper. 
2. In the six cases under review the gynecomasty is true. The gland presents the histological characteristics of the non-functioning female breast, with some differences. These consist of : the presence around the epithelial formations of a muff of reticular tissue; a tendency towards sclerosis of the interstitial connective tissue; the different type of cells with a common origin; and in some cases in the arrangement of the epithelium in various strata.

3. The presence of the periepithelial reticulum is due to functional stimulus producing more active division of the epithelium at the expense of the adventitial and endothelial cells of the capillaries.

4. The histological observation of the process of growth shows a complete parallelism with the development of the feminine breasts at the time of puberty.

5. The parallelism is increased by the fact that the breasts under consideration present true functional cycles at irregular periods, corresponding to morphological variations which consist of acinoblastic transitory activity, with neoformation of capillaries, active hyperemia and intensive œdema, which explain the erethism of the breasts, and the pains revealed by the patients (an analogy with the menstrual cycles of the breast in the woman).

6. With regard to the functional capacity of the neoformed gland, the presence of a colloidal substance in the interior of some acini makes it different from the female gland, and makes it atypical to a certain extent.

7. The condition here is that of a pathological growth which, on account of its peculiarities, belongs to hyperplastic processes: the male gland under an adequate hormonic stimulus grows and presents similarity with the pubescent development of the breast in the woman; the final product, however, assumes characteristics which put it on a plane of morphological inferiority.

8. Gynecomasty constitutes a process closely associated with the deficiency or suppression of the testicular endocrine function (orchi-epididimitis leprosy), which brings about alterations in the correlations of the endocrine system; and these alterations are, therefore, traced to the same cause, namely leprous infection.

9. This takes place in the cases under review, or in individuals who have already shown signs of an unbalanced endocrine state, or in other young boys during the critical 
period of puberty; in all of them there is shown to be a more or less grave orchitis.

10. All the endocrine syndromes illustrated present the common characteristic of hypogenitalism, tardy or pubescent, in relation to the date on which leprosy appeared.

11. Beside somatic hermaphroditism, in which the heterosexual characteristics develop themselves through an imperfect differentiation in the sexual embrionic stage and for which it is better to adopt the description of spontaneous pubescent, there must be placed the somatic hermaphroditism which appears in subjects who have passed the period of puberty, and which is probably due to the action of stimulus emanating from rudiments of the opposed genital gland, persisting in the individuals; these rudiments enter into action as a result of the abolition or inhibition of the testicular endocrine function. For this second type of somatic hermaphroditism, as there is the same mechanism of production, the authors suggest the description of acquired somatic hermaphroditism of adults. 